\title{
Risk Analysis Application in Aviation Sector with Intuitionistic Fuzzy TOPSIS Method
}

\author{
Ceren Ünlükall, $^{1, *}$, Mustafa Yücel ${ }^{2}$ \\ ${ }^{1}$ Department of Industrial Engineering, Munzur University, Tunceli, Turkey \\ ${ }^{2}$ Department of Business Administration, İnönü University, Malatya, Turkey
}

Received March 12, 2021; Revised May 7, 2021; Accepted June 6, 2021

\begin{abstract}
Cite This Paper in the following Citation Styles
(a): [1] Ceren Ünlükal, Mustafa Yücel, "Risk Analysis Application in Aviation Sector with Intuitionistic Fuzzy TOPSIS Method," Universal Journal of Management, Vol. 9, No. 5, pp. 140-149, 2021. DOI: 10.13189/ujm.2021.090502.
\end{abstract}

(b): Ceren Ünlükal, Mustafa Yücel (2021). Risk Analysis Application in Aviation Sector with Intuitionistic Fuzzy TOPSIS Method. Universal Journal of Management, 9(5), 140-149. DOI: 10.13189/ujm.2021.090502.

Copyright $\bigcirc 2021$ by authors, all rights reserved. Authors agree that this article remains permanently open access under the terms of the Creative Commons Attribution License 4.0 International License

\begin{abstract}
Failure Mode and Effects Analysis (FMEA) is one of the risk analysis techniques often used in many industries to recognize, assess, and avoid potential failures. FMEA consists of occurrence (O), severity (S) and detectability (D) of failures and by multiplying these components, the risk priority number (RPN) is obtained. The RPN value is an indicator used in prioritizing failures. Although FMEA is an analytical technique with strengths, such as helping to identify and reduce potential risks in processes and products, and being widely used, it has been criticized at some points. The main criticism is that different failures have the similar risk priority values and the same risk factor weight. Using FMEA alone may be insufficient in prioritizing the failures. It is not easy to appoint a mathematical number between 1 and 10 to $\mathrm{O}, \mathrm{S}$ and $\mathrm{D}$ risk factors by the experts and decision makers who make the risk assessment. At this point, the use of linguistic variables offered by the intuitionistic fuzzy logic approach provides convenience to decision makers and increases the accuracy of risk assessments. This study purposes to assess the risks that may arise throughout the production process of a company operating in the aviation industry with FMEA. Considering the possibility that risk factors are ignored and risk priorities cannot be determined correctly, intuitionistic fuzzy logic approach is integrated into the study. For this purpose, risk factors have been weighted by experts. In problem solving, failures have been prioritized by experts with the support of linguistic variables by using the Intuitionistic Fuzzy TOPSIS method.
\end{abstract}

Keywords Risk Analysis, Failure Prioritization, Failure Mode and Effects Analysis (FMEA), Intuitionistic
Fuzzy Logic, TOPSIS

\section{Introduction}

Many businesses operating in various industries face risks and dangers for different reasons. Businesses which want to be in markets where competition is intense and, continue to hold onto, should conduct risks nicely. To conduct risks, it is necessary to identify and analyse risks. With the corrective and / or preventive actions planned according to the analysis results, risks and failures are eliminated or minimized. In this way, the owned resources are used much more effectively, reducing losses, and increasing efficiency.

In businesses that produce with high volume and strategic raw materials / materials, processes that begin with a mistake may result in huge damages if timely measures are not taken. Failures in production processes are difficult to compensate after reaching the customer and are costly [1]. Therefore, businesses that make production to order must keep their risks under control and avoid situations that may harm customer satisfaction.

The high failure rates that occur during the production stages cause economic inefficiency in terms of the business and do groundwork for a loss of trust in customers. Failure Mode and Effects Analysis (FMEA), which is one of the most reliable engineering techniques used in analysis and evaluating risks, is used to handle failures in business activities in terms of Occurrence, Severity and Detection. 
Failures are prioritized according to the Risk Priority Number (RPN) obtained by multiplying the failure occurrence, severity and detection values determined by the experts. FMEA approach alone may be insufficient in prioritizing failures. In this study, the results were analysed by integrating the Intuitionistic Fuzzy Logic based TOPSIS approach into FMEA technique to eliminate the failures that arise in a company operating in the aviation sector and reduce the damage to the company.

The remained parts of the paper are as follows. Risk and risk management concepts are included in Section 2. The methodology and literature on FMEA are explained in Section 3. The case study is included in Section 4, while the discussions and conclusion are presented in the Section 5.

\section{Risk Concept and Risk Management}

The concept of risk is frequently used in various scientific fields such as banking, insurance, finance, decision making, management, trade and health. The concept of risk, which basically means the danger of loss or the possibility of being damaged, is also defined as uncertainty. Risk is an event that develops beyond expectations and can cause a negative situation. Risk is also expressed as the possibility of future situations, events or internal and external factors affecting the realization of goals and objectives.

In the OHSAS 18001 Occupational Health and Safety Management System, risk is expressed as the compound of the probability of occurrence of a dangerous event or exposure and the degree of severity of the injury or health impairment caused by the event or exposure, while in the ISO 31000 Risk Management System, it is described as the effect of uncertainty on goals.

Risk management is the process of determining, analysing and prioritizing risks to minimize the dangers that may occur during the activities of the businesses or to evaluate the opportunities that may arise in the best way. In general, risk management is the activities performed to reduce the risks to an acceptable level [2].

Risk management focuses on uncertainties and analysis of results and takes care to resolve these results in favor of the business. The main purpose in risk management is to establish a balance between risks and opportunities. The risk management process is activated when the ability to meet targets becomes uncertain. It is aimed to pursue and check risks. The process of risk management consists of the following steps.

Identifying risks is the first step of the process of risk management. At this stage, potential threats and opportunities that may affect the process are identified. In the second stage, the possibilities, effects and consequences of the risks are presented. Risk analysis is performed by measuring the risks and effects that are likely to occur. In the third stage, risk sizes obtained from the risk analysis are graded, evaluated and put in order.
Risk sizes are prioritized according to acceptable levels. In the fourth stage, it is necessary to plan remedial actions to eliminate the prioritized risks or bring them to the desired level. Corrective and preventive actions are planned toward from the highest risk value to the lowest risk value. At the last stage, the planned measures are put into practice and are reviewed to measure their effectiveness and remedial activities are revised when necessary.

\section{Methodology}

\subsection{Failure Mode and Effects Analysis}

In the 1960s, FMEA, which provided helpful outputs in the military and aviation industries, is one of the commonly used analytical tools and techniques to classify and remove potential or recognized failures and make risk management decisions to increase the reliability and safety of systems or processes and provide the necessary support [3]. This method, which is based on the principle of identifying and correcting possible troubles before the production process, ensures the continuousness of high-level quality products by aiming to identify the core reasons of risks and reduce their impacts [4-7]. FMEA is a simple type of analysis used to reveal potential problems in systems and predict possible unwanted results. This method is inductive and answers the question what if problems occur in this part for each part of the system. This determines the situations involving significant problems that may occur in the parts of the system and how much the whole system will be affected when this problem is encountered [8].

Prevention of potential failures with early intervention provides to decreasing system damages. FMEA, which serves to give priority to risks and mistakes; It contains three factors: Occurrence, Severity, and Detection. Occurrence or state of occurrence of a failure Occurrence; the degree of damage to the environment or the customer when a failure occurs Severity; the chance of detecting the potential failure before reaching the customer or the degree of noticeability is expressed as Detection. Risk Priority Number (RPN $=\mathrm{O} * \mathrm{~S} * \mathrm{D})$ is obtained by multiplication the mathematical numbers of risk factors [9]. The numerical equivalent of each risk factor is between 1 and 10, so the RPN value is an integer between 1 and 1000. Corrective and preventive actions are planned by ordering the obtained RPN values in descending order.

\subsection{Literature Review}

There are many studies in the literature conducted by adopting the FMEA approach. Some of these studies are included in Table 1. 
Table 1. Literature Review

\begin{tabular}{|c|c|c|}
\hline Author(s) & Method(s) & Application Field \\
\hline [10] & Intuitionistic fuzzy TOPSIS+FMEA & Pharmaceutical shipment network \\
\hline [11] & Fuzzy FMEA & Mining operations \\
\hline$[12]$ & $\begin{array}{c}\text { Best-worst method, Interval analysis, Grey relational } \\
\text { analysis+FMEA }\end{array}$ & Smartphone manufacturing \\
\hline [13] & Fuzzy MOORA+FMEA & Sustainable supplier selection \\
\hline [14] & Extended fuzzy MULTIMOORA, Fuzzy AHP+FMEA & Steel industry \\
\hline [15] & Fuzzy grey relational analysis+FMEA & LPG dispensing station \\
\hline [16] & Intuitionistic fuzzy TOPSIS+FMEA & Maritime industry \\
\hline [17] & Entropy weight method+FMEA & Gas station supply chain \\
\hline [18] & Intuitionistic fuzzy AHP, Intuitionistic fuzzy TOPSIS & Gas refinery \\
\hline [19] & Fuzzy AHP, QFD+FMEA & Shafting installation process \\
\hline [20] & Entropy method, TODIM+FMEA & Grinding wheel system \\
\hline [21] & ELECTRE TRI+FMEA & Dairy manufacturing industry \\
\hline [22] & IVIF-COPRAS, IVIF-ANP+FMEA & Hospital service \\
\hline [23] & Fuzzy and grey theory FMEA & Tanker equipment \\
\hline [24] & Kano model+FMEA & Airline services \\
\hline [25] & Fuzzy AHP, Entropy method, Fuzzy VIKOR+FMEA & General anesthesia process \\
\hline [26] & Fuzzy FMEA & Edible bird nest production process \\
\hline [27] & Fuzzy AHP, Fuzzy TOPSIS+FMEA & Automotive industry \\
\hline [28] & Fuzzy ANP, QFD+FMEA & Construction industry \\
\hline [29] & Dempster-Shafer evidence theory+FMEA & Aircraft turbine rotor blade \\
\hline
\end{tabular}

Although FMEA is widely used in many areas, it is criticized for being limited due to the uncertainty and problems experienced in prioritizing the detected failure modes [30-36]:

- Relative weights of $\mathrm{O}, \mathrm{S}$ and D risk factors are not considered in traditional FMEA. The importance of these factors may not be equal for every situation.

- Some failure modes with different $\mathrm{O}, \mathrm{S}$ and $\mathrm{D}$ numbers can have the same risk priority number.

- The formula used to determine the RPN value is open to discussion. There is no detailed justification in the literature that $\mathrm{O}, \mathrm{S}$, and $\mathrm{D}$ must be multiplication to calculate RPN.

- The RPN scale has a discrete structure, so it is difficult to derive a huge variety of values from 1 to 1000 from $\mathrm{O}, \mathrm{S}$ and $\mathrm{D}$ risk factors.

- It is difficult to perceive the three factors numerically. In FMEA, a lot of information can be explained with linguistic variables as possible, important or very high.

Considering the criticisms, it is seen that FMEA has not been used alone in recent years. Instead, using it in integration with fuzzy logic and Multi Criteria Decision Making (MCDM) techniques increases the success of problem solving and provides a more realistic perspective. For this reason, the Intuitionistic Fuzzy TOPSIS method was used in the study to determine the importance of potential failures more clearly by removing the negative aspects mentioned above.

\subsection{Intuitionistic Fuzzy TOPSIS}

Professor Lotfi A. Zadeh [37] laid the foundations of fuzzy logic by using the concept of Graded Sets. Zadeh has graded the memberships of the cluster members. In this way, he developed the concept of uncertainty and brought a new approach to the field of logic.

Atanassov [38], on the other hand, brought a new perspective to fuzzy logic and focused on the functions of membership and non-membership. The degree of hesitancy is important as well as whether the elements belong to a set or not. This approach has been described as Intuitionistic Fuzzy Logic.

TOPSIS (The Technique for Order Preference by Similarity to Ideal Solution), which has entered into the literature by Hwang and Yoon [39], is a MCDM method used to determine the best candidate closest to the positive ideal solution and the furthest to the negative ideal solution in the alternative set. The purpose of TOPSIS, which has a simple use, is to maximize benefit criteria and minimize cost criteria. It is often used for solving complex decision-making problems.

There is a lot of controversy about the risk factors for the probability of occurrence of the failure $(\mathrm{O})$, the 
severity of the failure (S), and the detection of the failure (D). Since linguistic evaluations are carried out by individuals in a relative manner, it has been assumed that the intuitionistic fuzzy (IF) set theory is suitable for dealing with the uncertainty of such evaluations and leading to more accurate results [40]. Ideally, risks should be assessed collectively and uncertainties in expert judgments to be used in the assessment should be minimized [10]. For this reason, the group decision model proposed by choosing the TOPSIS technique in the study was used to assess risk factors and failure elements based on the FMEA in an IF environment.

The process steps of the method used in prioritizing failures are as follows [41]:

Step 1: In the first stage, the weight of experts (decision makers) is calculated. Considering that there are $k$ experts in the decision maker team, linguistic variables are used to calculate the weights of these experts and the IF numbers corresponding to these linguistic variables are shown in Table 2. Let $U_{k}=\left\{\mu_{k}, v_{k}, \pi_{k}\right\}$ be an Intuitionistic Fuzzy Number (IFN) belonging to an expert of $k$. The following equations are used to calculate the weight of the expert.

Table 2. Linguistic Variables and IFN Used in Weighting Experts [41]

\begin{tabular}{|c|c|}
\hline Linguistic Variables & IFN Equivalent \\
\hline Very Important & $(0.90,0.10,0.00)$ \\
\hline Important & $(0.75,0.20,0.05)$ \\
\hline Average Important & $(0.50,0.45,0.05)$ \\
\hline Insignificant & $(0.35,0.60,0.05)$ \\
\hline Very Insignificant & $(0.10,0.90,0.00)$ \\
\hline
\end{tabular}

$$
\lambda_{k}=\frac{\left(\mu_{k}+\pi_{k}\left(\frac{\mu_{k}}{\mu_{k}+v_{k}}\right)\right)}{\sum_{k=1}^{n}\left(\mu_{k}+\pi_{k}\left(\frac{\mu_{k}}{\mu_{k}+v_{k}}\right)\right)} \text { and } \sum_{k=1}^{n} \lambda_{k}=1, k=(1,2, \ldots, n)
$$

If all experts are considered to be of same importance, the weight of expert $k$ can be calculated by (2):

$$
\lambda_{k}=\frac{1}{n} \text { and } \sum_{k=1}^{n} \lambda_{k}=1, k=(1,2, \ldots, n)
$$

Step 2: According to the experts' opinions, the aggregated IF decision matrix is created. Before the aggregation process, each expert's decision matrix must be established. For this, the linguistic variables shown in Tables 3, 4 and 5 are used. The IFWA operator is used to aggregate the decision matrices:
Table 3. Linguistic Variables and IFN Used in the Assessment of Failure Occurrence [41]

\begin{tabular}{|c|c|}
\hline Linguistic Variables & IFN Equivalent \\
\hline Very High & $(0.90,0.10,0.00)$ \\
\hline High & $(0.75,0.20,0.05)$ \\
\hline Average & $(0.50,0.45,0.05)$ \\
\hline Low & $(0.35,0.60,0.05)$ \\
\hline Very Low & $(0.10,0.90,0.00)$ \\
\hline
\end{tabular}

Table 4. Linguistic Variables and IFN Used in the Assessment of Failure Severity [41]

\begin{tabular}{|c|c|}
\hline Linguistic Variables & IFN Equivalent \\
\hline Hazardous Without Warning & $(1.00,0.00,0.00)$ \\
\hline High-Risk Warnings & $(0.90,0.10,0.00)$ \\
\hline Very Much & $(0.80,0.10,0.10)$ \\
\hline Much & $(0.70,0.20,0.10)$ \\
\hline Average & $(0.60,0.30,0.10)$ \\
\hline Low & $(0.50,0.40,0.10)$ \\
\hline Very Low & $(0.40,0.50,0.10)$ \\
\hline Inconsiderable & $(0.25,0.60,0.15)$ \\
\hline Very Inconsiderable & $(0.10,0.75,0.15)$ \\
\hline None & $(0.10,0.90,0.00)$ \\
\hline
\end{tabular}

Table 5. Linguistic Variables and IFN Used in the Assessment of Failure Detection [41]

\begin{tabular}{|c|c|}
\hline Linguistic Variables & IFN Equivalent \\
\hline Absolutely Impossible & $(1.00,0.00,0.00)$ \\
\hline Very Unlikely & $(0.90,0.10,0.00)$ \\
\hline Unlikely & $(0.80,0.10,0.10)$ \\
\hline Very Low & $(0.70,0.20,0.10)$ \\
\hline Low & $(0.60,0.30,0.10)$ \\
\hline Average & $(0.50,0.40,0.10)$ \\
\hline Relatively High & $(0.40,0.50,0.10)$ \\
\hline High & $(0.25,0.60,0.15)$ \\
\hline Very High & $(0.10,0.75,0.15)$ \\
\hline Absolutely Possible & $(0.10,0.90,0.00)$ \\
\hline
\end{tabular}

$$
\begin{aligned}
& r_{i j}=I F W A_{\lambda}\left(r_{i j}^{(1)}, r_{i j}^{(2)}, \ldots, r_{i j}^{(l)}\right)=\lambda_{1} r_{i j}^{(1)} \oplus \lambda_{2} r_{i j}^{(2)} \oplus \lambda_{3} r_{i j}^{(3)} \oplus \ldots \oplus \lambda_{l} r_{i j}^{(l)} \\
& r_{i j}=\left[1-\prod_{k=1}^{l}\left(1-\mu_{i j}^{(k)}\right)^{\lambda_{k}}, \prod_{k=1}^{l}\left(v_{i j}^{(k)}\right)^{\lambda_{k}}, \prod_{k=1}^{l}\left(1-\mu_{i j}^{(k)}\right)^{\lambda_{k}}-\prod_{k=1}^{l}\left(v_{i j}^{(k)}\right)^{\lambda_{k}}\right]
\end{aligned}
$$

$$
r_{i j}=\left(\mu_{A_{i}}\left(x_{j}\right), v_{A_{i}}\left(x_{j}\right), \pi_{A_{i}}\left(x_{j}\right)\right) \text { and }(i=1,2,3, \ldots, m ; j=1,2,3, \ldots, n) .
$$

The aggregated IF decision matrix is obtained as follows: 


$$
\begin{aligned}
& R=\left[\begin{array}{lll}
\mu_{F M_{1}}(O), v_{F M_{1}}(O), \pi_{F M_{1}}(O) & \mu_{F M_{1}}(S), v_{F M_{1}}(S), \pi_{F M_{1}}(S) & \mu_{F M_{1}}(D), v_{F M_{1}}(D), \pi_{F M_{1}}(D) \\
\mu_{F M_{2}}(O), v_{F M_{2}}(O), \pi_{F M_{2}}(O) & \mu_{F M_{2}}(S), v_{F M_{2}}(S), \pi_{F M_{2}}(S) & \mu_{F M_{2}}(D), v_{F M_{2}}(D), \pi_{F M_{2}}(D) \\
\vdots & & \\
\mu_{F M_{n}}(O), v_{F M_{n}}(O), \pi_{F M_{n}}(O) & \mu_{F M_{n}}(S), v_{F M_{n}}(S), \pi_{F M_{n}}(S) & \mu_{F M_{n}}(D), v_{F M_{n}}(D), \pi_{F M_{n}}(D)
\end{array}\right] \\
& R=\left[\begin{array}{ccc}
r_{1 O} & r_{1 S} & r_{1 D} \\
r_{2 O} & r_{2 S} & r_{2 D} \\
\vdots & \vdots & \vdots \\
r_{n O} & r_{n S} & r_{n D}
\end{array}\right]
\end{aligned}
$$

Step 3: The weight of risk factors is calculated. Suppose $w_{j}^{(k)}=\left(\mu_{j}^{(k)}, v_{j}^{(k)}, \pi_{j}^{(k)}\right)$ is an IFN assigned to criterion $j$ by expert $k$, then the weights of risk factors are determined through the IFWA operator as follows:

$$
\begin{aligned}
& w_{j}=I F W A_{\lambda}\left(w_{j}^{(1)}, w_{j}^{(2)}, \ldots, w_{j}^{(l)}\right)=\lambda_{1} w_{j}^{(1)} \oplus \lambda_{2} w_{j}^{(2)} \oplus \lambda_{3} w_{j}^{(3)} \oplus \ldots \oplus \lambda_{l} w_{j}^{(l)} \\
& w_{j}=\left[1-\prod_{k=1}^{l}\left(1-\mu_{j}^{(k)}\right)^{\lambda_{k}}, \prod_{k=1}^{l}\left(v_{j}^{(k)}\right)^{\lambda_{k}}, \prod_{k=1}^{l}\left(1-\mu_{j}^{(k)}\right)^{\lambda_{k}}-\prod_{k=1}^{l}\left(v_{j}^{(k)}\right)^{\lambda_{k}}\right]
\end{aligned}
$$

here $W=\left\lceil w_{1}, w_{2}, w_{3}, \ldots, w_{i}\right\rceil, w_{i}=\left\lceil\mu_{i}, v_{i}, \pi_{i}\right\rceil,(j=1,2, \ldots, n)$.

Step 4: Aggregated weighted IF decision matrix is determined. After finding the criterion weights $(W)$ and the aggregated IF decision matrix, the aggregated weighted IF decision matrix is formed as follows [38]:

$R \otimes W=\left\{\left\langle c, \mu_{F M_{i}}(x) \cdot \mu_{w}(c), v_{F M_{i}}(c)+v_{w}(c)-v_{F M_{i}}(c) \cdot v_{w}(c) \mid c \in X\right\rangle\right\}$

$\pi_{F M_{i} W}(c)=1-\mu_{F M_{i}}(c) \cdot \mu_{w}(c)-v_{F M_{i}}(c)-v_{w}(c)+v_{F M_{i}}(c) \cdot v_{w}(c)$

$R^{\prime}=\left[\begin{array}{ccc}\mu_{F M_{1} W}(O), v_{F M_{1} W}(O), \pi_{F M_{1}, W}(O) & \mu_{F M_{1} W}(S), v_{F M_{2} W}(S), \pi_{F M_{2} W}(S) & \mu_{F M_{1} W}(D), v_{F M_{1} W}(D), \pi_{F M_{1} W}(D) \\ \mu_{F M_{2} W}(O), v_{F M_{2} W}(O), \pi_{F M_{2} W}(O) & \mu_{F M_{2} W}(S), v_{F M_{2}, W}(S), \pi_{F M_{2} W}(S) & \mu_{F M_{2} W}(D), v_{F M_{2} W}(D), \pi_{F M_{2} W}(D) \\ \vdots & \vdots & \vdots \\ \mu_{F M_{2} W}(O), v_{F M_{n} W}(O), \pi_{F M_{0} W}(O) & \mu_{F M_{n} W}(S), v_{F M_{n} W}(S), \pi_{F M_{e} W}(S) & \mu_{F M_{e} W}(D), v_{F M_{n} W}(D), \pi_{F M_{2} W}(D)\end{array}\right]$

$$
R^{\prime}=\left[\begin{array}{ccc}
r_{1 O}^{\prime} & r_{1 S}^{\prime} & r_{1 D}^{\prime} \\
r_{2 O}^{\prime} & r_{2 S}^{\prime} & r_{2 D}^{\prime} \\
\vdots & \vdots & \vdots \\
r_{n O}^{\prime} & r_{n S}^{\prime} & r_{n D}^{\prime}
\end{array}\right]
$$

$$
r_{i j}^{\prime}=\left(\mu_{i j}^{\prime}, v_{i j}^{\prime}, \pi_{i j}^{\prime}\right)=\left(\mu_{F M W}(c), v_{F M W}(c), \pi_{F M W}(c)\right) \text { is }
$$
an element of the aggregated weighted IF decision matrix.

Step 5: Based on IFN, positive and negative ideal solution points are determined. Assuming that $J_{l}$ expresses the utility criterion and $J_{2}$ expresses the cost criterion, $\mathrm{FM}^{+}$ represents the IF positive ideal solution, while $\mathrm{FM}^{-}$ represents the IF negative ideal solution. $\mathrm{FM}^{+}$and $\mathrm{FM}^{-}$are expressed in the following equations:

$$
\begin{aligned}
& F M^{+}=\left(\left(\mu_{F M^{+} W}\left(c_{j}\right), v_{F M^{+} W}\left(c_{j}\right), \pi_{F M^{+} W}\left(c_{j}\right)\right) \text { and } F M^{-}=\left(\left(\mu_{F M^{\top} W}\left(c_{j}\right), v_{F M^{-} W}\left(c_{j}\right), \pi_{F M-W}\left(c_{j}\right)\right)\right.\right. \\
& \mu_{F M^{+} W}\left(c_{j}\right)=\left(\left\langle\max _{i} \mu_{F M^{+} W}\left(c_{j}\right) \mid j \in J_{1}\right\rangle,\left\langle\min _{i} \mu_{F M^{+} W}\left(c_{j}\right) \mid j \in J_{2}\right\rangle\right)
\end{aligned}
$$

$$
\begin{array}{r}
v_{F M^{+} W}\left(c_{j}\right)=\left(\left\langle\min _{i} v_{F M^{+} W}\left(c_{j}\right) \mid j \in J_{1}\right\rangle,\left\langle\max _{i} v_{F M^{+} W}\left(c_{j}\right) \mid j \in J_{2}\right\rangle\right) \\
\mu_{F M^{-} W}\left(c_{j}\right)=\left(\left\langle\min _{i} \mu_{F M^{-} W}\left(c_{j}\right) \mid j \in J_{1}\right\rangle,\left\langle\max _{i} \mu_{F M^{-} W}\left(c_{j}\right) \mid j \in J_{2}\right\rangle\right) \\
v_{F M^{-} W}\left(c_{j}\right)=\left(\left\langle\max _{i} v_{F M^{-} W}\left(c_{j}\right) \mid j \in J_{1}\right\rangle,\left\langle\min _{i} v_{F M^{-} W}\left(c_{j}\right) \mid j \in J_{2}\right\rangle\right)
\end{array}
$$

Step 6: Distance measurements are calculated using IF sets. In this step, the Euclidean distance formula is used to measure the distances. For each point, the distances from the IF positive ideal solution point $\left(S^{+}\right)$and the IF negative ideal solution point $\left(S^{+}\right)$are calculated as follows:

$S_{i}^{+}=\sqrt{\frac{1}{2 n} \sum_{j=1}^{n}\left[\left(\mu_{F M_{i} W}\left(c_{j}\right)-\mu_{F M^{+} W}\left(c_{j}\right)\right)^{2}+\left(v_{F M_{i} W}\left(c_{j}\right)-v_{F M^{+} W}\left(c_{j}\right)\right)^{2}+\left(\pi_{F M^{W} W}\left(c_{j}\right)-\pi_{F M^{+} W}\left(c_{j}\right)\right)^{2}\right]}$

$S_{i}^{-}=\sqrt{\frac{1}{2 n} \sum_{j=1}^{n}\left[\left(\mu_{F M, W}\left(c_{j}\right)-\mu_{F M-W}\left(c_{j}\right)\right)^{2}+\left(v_{F M_{W} W}\left(c_{j}\right)-v_{F M-W}\left(c_{j}\right)\right)^{2}+\left(\pi_{F M, W}\left(c_{j}\right)-\pi_{F M-W}\left(c_{j}\right)\right)^{2}\right]}$

Step 7: The relative closeness coefficient $\left(C C_{i}\right)$ required for the intuitionistic ideal solution is calculated individually. $C C_{i}$ can be calculated as follows:

$$
C C_{i}=\frac{S_{i}^{-}}{S_{i}^{-}+S_{i}^{+}}, 0 \leq C C_{i} \leq 1
$$

Step 8: The calculated relative closeness coefficients are ranked in descending order. This ranking also expresses risk priority.

\section{Case Study}

The study was carried out in Eskişehir (in Turkey) in a company that operates in the field of precision aircraft engine parts and structural parts manufacturing, engineering, fixture and tool design manufacturing, special processes and quality control, and machining for the aviation industry.

The company, which has a machine park consisting of 21 vertical lathes, 27 horizontal lathes, 8 milling machines and 4 precision measuring devices and more than 200 employees, is one of the high-capacity companies operating in the sector for more than 25 years. Factors such as wide machine park, huge number of products and employees, flexible and variable customer demands increase the complexity of the works in the company. Due to increasing customer complaints, rework part rates, delayed deliveries and rising costs, the company wanted to solve the problems it faced. The company, which could not find the substantial solutions within its own structure, wanted to stop the growth of the problems by taking external consultancy services. It has been determined that most of the problems occur in parts that are ignored during the production process, but mostly produced. In 
order to reduce the problems in a short time, studies have started with the product that poses a high risk. With the precautions to be taken according to the results of the analysis to be made, firstly, an improvement will be provided throughout the part dealt with, and then these precautions will be implemented across all products. Thus, the company wants to take an important step in achieving its goals and realizing its missions by ensuring customer satisfaction with sustainable production assurance. Due to these demands, cooperation was established with the company and necessary analyses were made. The main purpose of this study is to identify the risks / failures that occur or may occur along the production process of a critical aircraft engine part produced in the company, and to realize a safer production process by eliminating these risks / failures.

It is aimed to reduce the failures and increase the quality performance by defining the failures that may occur along the manufacturing process. For this purpose, a team of two experts working as a quality engineer in the quality department has been formed. Using the failure records and the experiences of the team members, the product with the most problems in the production process and the problems that occurred during the manufacturing process of this product were determined. Risk analysis studies were evaluated with the IF TOPSIS method, and failure priorities were determined.
Shaft is one of the most produced products in the company and 2 vertical and 1 horizontal turning lathes are allocated only for this product, without changing the turning program. Shaft is one of the aircraft engine parts and is critical. Therefore, it is not possible to estimate the value of any failure that may occur. Considering all these features, it is inevitable to carry out risk analysis on this product.

Risk analysis does not only ensure that the customer receives fault-free parts; at the same time, by producing the right product at the first time, direct labor time and costs are reduced, the cycle time of the product is reduced, the consumables used are reduced, the rework times are reduced and the capacity utilization rate is increased.

\subsection{Risk Analysis Application}

To make the risk assessment, first, the failures that may occur in the production process of the product named HPT AFT SHAFT must be defined. The failures and their effects are specified in Table 6.

After failures are identified, the steps required for risk analysis application are as follows:

Step 1: Since the weight of the experts is considered equal, the weight is calculated according to (2).

The weight of each expert is determined as $\lambda_{k}=\frac{1}{2}=0,50$.

Table 6. Definition of Failures Occurring in the Factory and Failures Effects

\begin{tabular}{|c|c|c|c|}
\hline $\begin{array}{l}\text { Failure } \\
\text { Modes }\end{array}$ & Failure & Failure Description & Failure Effect \\
\hline FM1 & $\begin{array}{l}\text { Measure } \\
\text { Failure }\end{array}$ & Measures out of tolerance limits & Part does not fit properly \\
\hline FM2 & $\begin{array}{l}\text { Surface } \\
\text { Defects }\end{array}$ & $\begin{array}{l}\text { Failures caused by felt, cutting and measuring } \\
\text { tool, fixture seating point marks }\end{array}$ & Affects product function and appearance \\
\hline FM3 & Dent & Cavities in the part due to various reasons & $\begin{array}{l}\text { Surface quality deteriorates, risk of edge breakage } \\
\text { increases, product function is affected }\end{array}$ \\
\hline FM4 & Crushed & $\begin{array}{c}\text { Cracks, breaks or deep marks on some parts of } \\
\text { the product }\end{array}$ & $\begin{array}{c}\text { The functionality of the product deteriorates, and } \\
\text { the desired properties cannot be obtained }\end{array}$ \\
\hline FM5 & Set & $\begin{array}{l}\text { Failure to machine the part correctly due to burr } \\
\text { or insert failures during machining }\end{array}$ & $\begin{array}{l}\text { The function of the final product is affected, and } \\
\text { the desired product cannot be obtained }\end{array}$ \\
\hline FM6 & $\begin{array}{l}\text { Non-Occurring } \\
\text { Measure }\end{array}$ & $\begin{array}{l}\text { The absence of features such as edges, corners, } \\
\text { angles, etc. }\end{array}$ & The desired product cannot be obtained \\
\hline
\end{tabular}

Table 7. Risk Evaluation According to Expert Opinions

\begin{tabular}{|c|c|c|c|}
\hline Expert -1 & Occurrence & Severity & Detection \\
\hline FM1 & Very High & Very Much & Unlikely \\
\hline FM2 & Low & Very Inconsiderable & Average \\
\hline FM3 & Average & Inconsiderable & Average \\
\hline FM4 & Very Low & Inconsiderable & Average \\
\hline FM5 & Average & Very Low & Detection \\
\hline FM6 & Average & Much & Low \\
\hline Expert -2 & Occurrence & Severity & Average \\
\hline FM1 & Very High & High-Risk Warnings & Relatively High High \\
\hline FM2 & Average & Low Low & Very High \\
\hline FM3 & Average & Low & Very Unlikely \\
\hline FM4 & Low & Much & Very Much \\
\hline FM5 & Very Low & Low &
\end{tabular}


Table 8. Decision Matrix

\begin{tabular}{|c|c|c|c|c|c|c|c|c|c|}
\hline Expert -1 & \multicolumn{3}{|c|}{$\mathrm{O}$} & \multicolumn{3}{|c|}{$\mathrm{S}$} & \multicolumn{3}{|c|}{$\mathrm{D}$} \\
\hline FM1 & 0.9 & 0.1 & 0 & 0.8 & 0.1 & 0.1 & 0.6 & 0.3 & 0.1 \\
\hline FM2 & 0.35 & 0.6 & 0.05 & 0.1 & 0.75 & 0.15 & 0.8 & 0.1 & 0.1 \\
\hline FM3 & 0.5 & 0.45 & 0.05 & 0.25 & 0.6 & 0.15 & 0.5 & 0.4 & 0.1 \\
\hline FM4 & 0.1 & 0.9 & 0 & 0.25 & 0.6 & 0.15 & 0.5 & 0.4 & 0.1 \\
\hline FM5 & 0.5 & 0.45 & 0.05 & 0.4 & 0.5 & 0.1 & 0.5 & 0.4 & 0.1 \\
\hline FM6 & 0.5 & 0.45 & 0.05 & 0.7 & 0.2 & 0.1 & 0.8 & 0.1 & 0.1 \\
\hline Expert -2 & \multicolumn{3}{|c|}{$\mathrm{O}$} & \multicolumn{3}{|c|}{$\mathrm{S}$} & \multicolumn{3}{|c|}{$\mathrm{D}$} \\
\hline FM1 & 0.9 & 0.1 & 0 & 0.9 & 0.1 & 0 & 0.6 & 0.3 & 0.1 \\
\hline FM2 & 0.5 & 0.45 & 0.05 & 0.4 & 0.5 & 0.1 & 0.5 & 0.4 & 0.1 \\
\hline FM3 & 0.5 & 0.45 & 0.05 & 0.5 & 0.4 & 0.1 & 0.4 & 0.5 & 0.1 \\
\hline FM4 & 0.35 & 0.6 & 0.05 & 0.5 & 0.4 & 0.1 & 0.4 & 0.5 & 0.1 \\
\hline FM5 & 0.1 & 0.9 & 0 & 0.7 & 0.2 & 0.1 & 0.7 & 0.2 & 0.1 \\
\hline FM6 & 0.35 & 0.6 & 0.05 & 0.8 & 0.1 & 0.1 & 0.9 & 0.1 & 0 \\
\hline
\end{tabular}

Table 9. Decision Matrix

\begin{tabular}{|c|c|c|c|c|c|c|c|c|c|}
\cline { 2 - 11 } \multicolumn{1}{c|}{} & \multicolumn{3}{c|}{ O } & \multicolumn{3}{c|}{ S } & \multicolumn{2}{c|}{ D } \\
\hline FM1 & 0.900 & 0.100 & 0.000 & 0.859 & 0.100 & 0.041 & 0.600 & 0.300 & 0.100 \\
\hline FM2 & 0.430 & 0.520 & 0.050 & 0.265 & 0.612 & 0.122 & 0.684 & 0.200 & 0.116 \\
\hline FM3 & 0.500 & 0.450 & 0.050 & 0.388 & 0.490 & 0.122 & 0.452 & 0.447 & 0.101 \\
\hline FM4 & 0.235 & 0.735 & 0.030 & 0.388 & 0.490 & 0.122 & 0.452 & 0.447 & 0.101 \\
\hline FM5 & 0.329 & 0.636 & 0.034 & 0.576 & 0.316 & 0.108 & 0.613 & 0.283 & 0.104 \\
\hline FM6 & 0.430 & 0.520 & 0.050 & 0.755 & 0.141 & 0.104 & 0.859 & 0.100 & 0.041 \\
\hline
\end{tabular}

Step 2: Expert opinions are determined according to the linguistic variables shown in Tables 3, 4 and 5 and the aggregated IF decision matrix is formed. The opinions of the experts are shown in Table 7.

Evaluations made with linguistic variables are transformed into IFN as indicated in Table 8.

Expert opinions are aggregated using the IFWA operator.

Step 3: The weight of risk factors is calculated to weight the decision matrix.

Table 10. Experts' Evaluations of Risk Factors

\begin{tabular}{|c|c|c|c|}
\cline { 2 - 4 } \multicolumn{1}{c|}{} & O & S & D \\
\hline Expert -1 & High & Very high & Average \\
\hline Expert -2 & Very high & Very high & High \\
\hline
\end{tabular}

Table 11. Risk Factors Weights

\begin{tabular}{|c|c|c|c|c|c|l|l|l|l|l|}
\cline { 2 - 9 } \multicolumn{1}{c|}{} & \multicolumn{3}{c|}{$\mathrm{O}$} & \multicolumn{3}{c|}{$\mathrm{S}$} & \multicolumn{2}{c|}{$\mathrm{D}$} \\
\hline $\mathrm{W}$ & 0.842 & 0.141 & 0.017 & 0.900 & 0.100 & 0.000 & 0.646 & 0.300 & 0.054 \\
\hline
\end{tabular}

Step 4: The aggregated weighted IF decision matrix is determined according to the weights of the risk factors.

Table 12. Aggregated Weighted Decision Matrix

\begin{tabular}{|l|l|l|l|l|l|l|l|l|l|}
\cline { 2 - 10 } \multicolumn{1}{c|}{} & \multicolumn{3}{c}{ O } & \multicolumn{3}{c|}{ S } & \multicolumn{2}{c|}{ D } \\
\hline FM1 & 0.758 & 0.227 & 0.015 & 0.773 & 0.190 & 0.037 & 0.388 & 0.510 & 0.102 \\
\hline FM2 & 0.362 & 0.588 & 0.051 & 0.239 & 0.651 & 0.110 & 0.442 & 0.440 & 0.118 \\
\hline FM3 & 0.421 & 0.528 & 0.051 & 0.349 & 0.541 & 0.110 & 0.292 & 0.613 & 0.095 \\
\hline FM4 & 0.198 & 0.772 & 0.030 & 0.349 & 0.541 & 0.110 & 0.292 & 0.613 & 0.095 \\
\hline FM5 & 0.277 & 0.688 & 0.035 & 0.518 & 0.385 & 0.097 & 0.396 & 0.498 & 0.106 \\
\hline FM6 & 0.362 & 0.588 & 0.051 & 0.680 & 0.227 & 0.093 & 0.555 & 0.370 & 0.075 \\
\hline
\end{tabular}

Step 5: Based on IFN, positive and negative ideal solution points are determined. 
Table 13. Positive and Negative Ideal Solutions

\begin{tabular}{|c|c|c|c|c|c|c|c|c|c|}
\cline { 2 - 10 } \multicolumn{1}{c|}{} & \multicolumn{3}{c|}{$\mathrm{O}$} & \multicolumn{3}{c|}{$\mathrm{S}$} & \multicolumn{3}{c|}{$\mathrm{D}$} \\
\hline $\mathrm{FM}^{+}$ & 0.758 & 0.227 & 0.015 & 0.773 & 0.190 & 0.037 & 0.555 & 0.370 & 0.075 \\
\hline $\mathrm{FM}^{-}$ & 0.198 & 0.772 & 0.030 & 0.239 & 0.651 & 0.110 & 0.292 & 0.613 & 0.095 \\
\hline
\end{tabular}

Step 6: Distance measurements are calculated using IF sets.

Step 7: The relative closeness coefficient $\left(C C_{i}\right)$ required for the intuitionistic ideal solution is calculated.

Table 14. Distance Measures and Closeness Coefficients

\begin{tabular}{|c|c|c|c|c|}
\cline { 2 - 5 } \multicolumn{1}{c|}{} & $\mathrm{S}_{\mathrm{i}}{ }^{+}$ & $\mathrm{S}_{\mathrm{i}}^{-}$ & $C C_{\mathrm{i}}$ & Rank \\
\hline FM1 & 0.090 & 0.435 & 0.829 & 1 \\
\hline FM2 & 0.368 & 0.138 & 0.273 & 5 \\
\hline FM3 & 0.327 & 0.150 & 0.314 & 4 \\
\hline FM4 & 0.418 & 0.064 & 0.132 & 6 \\
\hline FM5 & 0.314 & 0.176 & 0.360 & 3 \\
\hline FM6 & 0.224 & 0.307 & 0.578 & 2 \\
\hline
\end{tabular}

Step 8: In Table 14, the distance of the values belonging to each failure mode to the positive and negative ideal solution set is calculated and arranged according to the closeness coefficients in descending order. This order also refers to the order of risk priority. Accordingly, the highest risk priority is the measurement failure with FM1 code. This is followed by FM6, FM5, FM3, FM2 and FM4 respectively.

\section{Discussions and Conclusions}

FMEA is an effective method for designing and planning product and process by determining risks in various processes and preventing or reducing their effects at early stages. In traditional FMEA, RPN values are obtained by multiplication $\mathrm{O}, \mathrm{S}, \mathrm{D}$ and the degree of criticality is determined. However, this practice has some disadvantages such as multiplying different values of risk factors and obtaining the same RPN value without considering the weights of risk factors.

Despite advances in risk assessment, methods such as FMEA have gained wide-ranging applicability due to their simplicity and less time expenditure. On the other hand, FMEA method is criticised and FMEA application is narrow due to its inherent uncertainty, various restrictions and difficult capture of objectivity. Risk assessment in FMEA is a specific complex task that is often performed with the experience and intuition of team members.

The integrated approach proposed in this study, which aims to eliminate critical failures in a business operating in the aviation industry, strategically evaluates the link established between risk analysis and MCDM methods. The approach starts from the need to define all of the risks through FMEA to analyse the risk factors of the system under study in depth. The IF TOPSIS method is used to prioritize the failures according to various evaluation criteria to rank the importance of all failure modes. IF TOPSIS is powerful at the same time in directing data uncertainty as it uses IFN. Risk factors were weighted by the aggregation of collective decisions made by a group of experts. This application was carried out in prospect of that risk factors may not have the same weight. Values of different weighted risk factors estimated by IF expressions are given based on expert judgment. This is an important progress in FMEA area, as giving distinctive weights to factors using IF logic adds a new perspective to FMEA. Then, IF TOPSIS was applied to analyse possible failure modes and rank them according to risk priorities, and linguistic variables were used.

The results obtained from this study are both guiding and warning to other companies operating in the same / similar sector, as well as improving the production processes in other products of the company. Companies that realize the risks / failures that have not yet occurred in their processes can easily take precautions or apply to written studies / research reports such as this to solve similar problems. Thus, the risks either never occur or cause minimal damage.

There are several important issues that limit this study. Expert opinions in calculating RPN or determining the weights of risk factors affect the priority order of failure modes. It should be considered that if there is any change in the evaluations of decision makers, the order of priority will change. Therefore, repeating the study with different experts and examining the consequence of the changes will contribute to the literature.

A recommendation has been provided against the limitations expressed in the paragraph above. Based on the company examined in this study, it is thought that it will be beneficial to restructure the study by increasing the sample size in the cluster formed by the companies operating in the aviation sector and to examine the results. It can be aimed to produce solutions to the problems that occur on a sectoral basis. In this way, problems can be more easily generalized and dealt with in a radical way and permanent solutions are developed.

Other suggestion to be presented for the development of the proposed method is to use MCDM techniques such as AHP or ANP in determining the risk factor weights that can cause objective results in the process of evaluating failure modes. It may be important to what extent the weights determined in this way will affect the result. Another suggestion is to use other MCDM methods in problem solving in addition to TOPSIS in risk assessment 
of failure modes and to look at the differences in risk priority order.

\section{REFERENCES}

[1] M. Zerenler and K. Karaboğa. Müşteri Memnuniyetinin Sağlanmasında Hataların Önlenmesine Yönelik Üretim Odaklı Bir Bakış Açısı: Poka-Yoke Sistemleri, Selçuk University Journal of Institute of Social Sciences, Vol. Dr. Mehmet YILDIZ Special Edition, 263-276, 2014.

[2] P. R. Garvey. Analytical Methods for Risk Management, Chapman and Hall/CRC, New York, 2008.

[3] S. Shi, H. Fei, and X. Xu. Application of a FMEA Method Combining Interval 2-Tuple Linguistic Variables and Grey Relational Analysis in Preoperative Medical Service Process, IFAC-PapersOnLine, Vol. 52, No. 13, 1242-1247, 2019.

[4] C. L. Chang, C. C. Wei, and Y. H. Lee. Failure Mode and Effects Analysis Using Fuzzy Method and Grey Theory, Kybernetes, Vol. 28, No. 9, 1072-1080, 1999.

[5] C. Kahraman, I. Kaya, and Ö. Şenvar. Healthcare Failure Mode and Effects Analysis Under Fuzziness, Human and Ecological Risk Assessment, Vol. 19, No. 2, 538-552, 2013.

[6] P. Mizrak Özfirat. Bulanık Önceliklendirme Metodu ve Hata Türü ve Etkileri Analizini Birleştiren Yeni Bir Risk Analizi Yöntemi, Journal of the Faculty of Engineering and Architecture of Gazi University, Vol. 29, No. 4, 755-768, 2014.

[7] W. C. Ng, S. Y. Teh, H. C. Low, and P. C. Teoh. The Integration of FMEA with Other Problem Solving Tools: A Review of Enhancement Opportunities, Journal of Physics: Conference Series, Vol. 890, No. 1, 1-7, 2017.

[8] İ. Üçkardeş and D. Ünal. Risk Analizi ve Havacıllk Sektöründe Kaza Risklerinin İncelenmesi, Çukurova University Journal of Science and Engineering, Vol. 27, No. 2, 174-181, 2012.

[9] C. Ünlükal, M. Şenel, and B. Şenel. Risk Assessment with Failure Mode and Effects Analysis and Grey Relational Analysis Method in Plastic Injection Process, ITM Web of Conferences, Vol. 22, 1-7, 2018.

[10] S. Faghih-Roohi, A. Akcay, Y. Zhang, E. Shekarian, and E. de Jong. A Group Risk Assessment Approach for the Selection of Pharmaceutical Product Shipping Lanes, International Journal of Production Economics, Vol. 229, No. April, 1-13, 2020.

[11] J. Balaraju, M. Govinda Raj, and C. S. Murthy. Fuzzy-FMEA Risk Evaluation Approach for LHD Machine-A Case Study, Journal of Sustainable Mining, Vol. 18, No. 4, 257-268, 2019.

[12] H. W. Lo and J. J. H. Liou. A Novel Multiple-Criteria Decision-Making-Based FMEA Model for Risk Assessment, Applied Soft Computing Journal, Vol. 73, 684-696, 2018.

[13] A. Arabsheybani, M. M. Paydar, and A. S. Safaei. An Integrated Fuzzy MOORA Method and FMEA Technique for Sustainable Supplier Selection Considering Quantity Discounts and Supplier's Risk, Journal of Cleaner
Production, Vol. 190, 577-591, 2018.

[14] R. Fattahi and M. Khalilzadeh. Risk Evaluation Using a Novel Hybrid Method Based on FMEA, Extended MULTIMOORA, and AHP Methods under Fuzzy Environment, Safety Science, Vol. 102, No. October, 290$300,2018$.

[15] A. Maniram Kumar, S. Rajakarunakaran, P. Pitchipoo, and R. Vimalesan. Fuzzy Based Risk Prioritisation in an Auto LPG Dispensing Station, Safety Science, Vol. 101, No. May, 231$247,2018$.

[16] M. Şenel, B. Şenel, and C. A. Havle. Risk Analysis of Ports in Maritime Industry in Turkey using FMEA Based Intuitionistic Fuzzy TOPSIS Approach, ITM Web of Conferences, Vol. 22, 1-10, 2018.

[17] Y. Liu, Z. Kong, and Q. Zhang. Failure Modes and Effects Analysis (FMEA) for the Security of the Supply Chain System of the Gas Station in China, Ecotoxicology and Environmental Safety, Vol. 164, No. 5, 325-330, 2018.

[18] M. Yazdi. Risk Assessment Based on Novel Intuitionistic Fuzzy-Hybrid-Modified TOPSIS Approach, Safety Science, Vol. 110, No. March, 438-448, 2018.

[19] Q. Guo, K. Sheng, Z. Wang, X. Zhang, H. Yang, and R. Miao. Research on Element Importance of Shafting Installation Based on QFD and FMEA, Procedia Engineering, Vol. 174, 677-685, 2017.

[20] J. Huang, Z. Li, and H. C. Liu. New Approach for Failure Mode and Effect Analysis Using Linguistic Distribution Assessments and TODIM Method, Reliability Engineering and System Safety, Vol. 167, No. January, 302-309, 2017.

[21] A. Certa, M. Enea, G. M. Galante, and C. M. La Fata. ELECTRE TRI- Based Approach to the Failure Modes Classification on the Basis of Risk Parameters: An Alternative to the Risk Priority Number, Computers and Industrial Engineering, Vol. 108, 100-110, 2017.

[22] L. E. Wang, H. C. Liu, and M. Y. Quan. Evaluating the Risk of Failure Modes with a Hybrid MCDM Model under Interval-Valued Intuitionistic Fuzzy Environments, Computers and Industrial Engineering, Vol. 102, 175-185, 2016.

[23] Q. Zhou and V. V. Thai. Fuzzy and Grey Theories in Failure Mode and Effect Analysis for Tanker Equipment Failure Prediction, Safety Science, Vol. 83, 74-79, 2016.

[24] K. C. Hu and M. W. Hsiao. Quality Risk Assessment Model for Airline Services Concerning Taiwanese Airlines, Journal of Air Transport Management, Vol. 53, 177-185, 2016.

[25] H. C. Liu, J. X. You, X. Y. You, and M. M. Shan. A Novel Approach for Failure Mode and Effects Analysis Using Combination Weighting and Fuzzy VIKOR Method, Applied Soft Computing Journal, Vol. 28, 579-588, 2015.

[26] C. H. Jong, K. M. Tay, and C. P. Lim. Application of the Fuzzy Failure Mode and Effect Analysis Methodology to Edible Bird Nest Processing, Computers and Electronics in Agriculture, Vol. 96, 90-108, 2013.

[27] A. C. Kutlu and M. Ekmekçioğlu. Fuzzy Failure Modes and Effects Analysis by Using Fuzzy TOPSIS-Based Fuzzy AHP, Expert Systems with Applications, vol. 39, No. 1, 61-67, 2012. 
[28]H. T. Liu and Y. lin Tsai. A Fuzzy Risk Assessment Approach for Occupational Hazards in the Construction Industry, Safety Science, Vol. 50, No. 4, 1067-1078, 2012.

[29] J. Yang, H. Z. Huang, L. P. He, S. P. Zhu, and D. Wen. Risk Evaluation in Failure Mode and Effects Analysis of Aircraft Turbine Rotor Blades Using Dempster-Shafer Evidence Theory under Uncertainty, Engineering Failure Analysis, Vol. 18, No. 8, 2084-2092, 2011.

[30] M. Ben-Daya and A. Raouf. A revised failure mode and effects analysis model, International Journal of Quality and Reliability Management, Vol. 13, No. 1, 43-47, 1996.

[31] J. B. Bowles. An Assessment of RPN Prioritization in a Failure Modes Effects and Criticality Analysis, Journal of the IEST, Vol. 47, 51-56, 2004.

[32] M. Braglia, M. Frosolini, and R. Montanari. Fuzzy Criticality Assessment Model for Failure Modes and Effects Analysis, International Journal of Quality and Reliability Management, Vol. 20, No. 4, 503-524, 2003.

[33] K. S. Chin, Y. M. Wang, G. Ka Kwai Poon, and J. B. Yang. Failure Mode and Effects Analysis Using a Group-Based Evidential Reasoning Approach, Computers and Operations Research, Vol. 36, No. 6, 1768-1779, 2009.

[34] W. Gilchrist. Modelling Failure Modes and Effects Analysis,
International Journal of Quality and Reliability Management, Vol. 10, No. 5, 16-23, 1993.

[35] A. Pillay and J. Wang. Modified Failure Mode and Effects Analysis Using Approximate Reasoning, Reliability Engineering \& System Safety, vol. 79, 69-85, 2003.

[36] N. R. Sankar and B. S. Prabhu. Modified Approach for Prioritization of Failures in a System Failure Mode and Effects Analysis, International Journal of Quality and Reliability Management, Vol. 18, No. 3, 324-335, 2001.

[37] L. A. Zadeh. Fuzzy Sets, Information and Control, Vol. 8, 338-353, 1965.

[38] K. T. Atanassov. Intuitionistic Fuzzy Sets, Fuzzy Sets and Systems, Vol. 20, No. 1, 87-96, 1986.

[39] C. L. Hwang and K. Yoon. Multiple Attributes Decision Making Methods and Applications, Springer, Berlin, 1981.

[40] H. Sayyadi Tooranloo, A. S. Ayatollah, and S. Alboghobish. Evaluating Knowledge Management Failure Factors Using Intuitionistic Fuzzy FMEA Approach, Knowledge and Information Systems, Vol. 57, No. 1, 183-205, 2018.

[41] H. Sayyadi Tooranloo and A. sadat Ayatollah. A Model for Failure Mode and Effects Analysis Based on Intuitionistic Fuzzy Approach, Applied Soft Computing Journal, Vol. 49, 238-247, 2016. 